\title{
New Method for Determination of Residual Strength Parameters and Critical Damage Value
}

\author{
Qiao Jiang 1,2, Jianlin $\mathrm{Li}^{1,2}$, Yanhai Wang ${ }^{2}$, Zuosen $\mathrm{Luo}^{2}$, Tao $\mathrm{Li}^{2}$, Hengbin Zhang², Eleyas Assefa ${ }^{3}$, \\ Huafeng Deng ${ }^{2, *}$
}

\author{
1 College of Hydraulic\& Environmental Engineering, \\ China Three Gorges University, \\ Yichang City, Hubei Province, 443002, China \\ 2 Key Laboratory of Geological Hazards on Three Gorges Reservoir Area of Ministry of Education, \\ China Three Gorges University, Yichang City, Hubei Province, 443002, China \\ ${ }^{3}$ College of Architecture and Civil Engineering, Addis Ababa Science and Technology University, \\ Addis Ababa, P.O.B. 16417, Ethiopia \\ *Corresponding author, e-mail: dhf8010@ctgu.edu.cn
}

Received: 30 January 2019, Accepted: 19 March 2019, Published online: 25 April 2019

\begin{abstract}
Residual strength and critical damage parameters are worthy to evaluate the stability of engineered rock masses. In this paper, new thinking, repeated load test on a single specimen was proposed to measure the residual strength of the rock. And author proposed to modify the critical damage value based on residual constitutive energy. The test results showed that: (1) the residual strength of rock is mainly controlled by the confining pressure, without a clear relationship with the confining pressure and stress path of the initial loading failure. (2) The residual strength parameters of the rock specimens under repeated loading test are consistent with the conventional triaxial test. Most importantly, the proposed method is relatively less dispersion, cheap, reliable, and time-saving. (3) The corrected critical damage value was reasonable. Relevant test methods can provide a useful reference for the determination of residual strength parameters and critical damage value.
\end{abstract}

\section{Keywords}

single specimen method, repeated loading, residual strength, critical damage value, dispersion

\section{Introduction}

Generally, rock mechanics tests are destructive tests. In the conventional triaxial compression test, a rock specimen can only have one set of major and minor principal stress $\left(\sigma_{1}, \sigma_{3}\right)$. The failure envelope provides the rock strength parameters. Multiple test method evaluates the strength of rock specimens. This method is not only costly and time-taking, but various types of rocks are heterogeneous with various microscopic cracks and pores due to the long-term geological processes. There is a variation in the test results, even for the same rock specimens. Anomalously, the confining pressure increases while the axial stress decreases [1]. Though repeat testing increases the accuracy of test results, there is still a challenge in the analysis of conventional rock mechanics test results. In rock engineering design, proper rock mass mechanical strength parameters need to be determined [2]. To overcome this problem, many researcher investigated sample preparation precision, sample screening, and test result correction [3-4], which provides a good foundation for improving the accuracy of test results. However, it is also fundamentally impossible to avoid the effect of specimen variations on the accuracy of the test results.

In the 1980s, some scholars proposed a single specimen test method or multistage loading using a single specimen [5-13]. Experimental studies were conducted on many types of rocks (such as sandstone, marble, mudstone, etc.) by different investigators using a single specimen test method. Moreover, the difference between a single specimen and the conventional multiple specimen test methods were analyzed [5-12]. Li et al. [13] determined the unloading strength parameters using a single plug multistage unloading failure test method. $\mathrm{Xu}$ et al. [14] determines a soft rock single test sheared yield strength of different pressure, drawing shear yield strength in vertical section 
and comparing the experimental results of single test sample shear experiment with the experimental results of many test sample shear experiments and numerical value is very close. Yong et al. [15], and Yan et al. [16] employed a single specimen test method for composite materials using direct shear test. The single specimen loading method has clear and simple procedures to improve the accuracy of the test results. It has been widely used and recognized in rock mechanics tests. Similarly, this method has been used by the International Society of Rock Mechanics to evaluate the compressive strength of the rock [6]. However, relevant studies have shown that [17-18], in the single specimen loading process, each stage of multistage loading results in damage in the rock specimen and the next load step should be applied before the failure so it is below the real failure curve. As a result, an exception of the first stage, the strength is significantly smaller than the Conventional triaxial compressive strength under the same confining pressure. Liu et al. [17], and Song et al. [18] considered the damaging effect of multistage loading and proposed the corresponding correction method. Pagoulatos [19] proposed a cut point based on volumetric strain. The established failure envelope characteristics showed a good agreement with single stage conventional triaxial tests.

In many engineering projects, the actual stress state of the rock mass is complex and predominantly in the postpeak stage. Many slopes and tunnels develop cracks on the rock mass. Furthermore, the reliability of rock engineering project depends on the accuracy of strength and damage parameters [20]. Based on thermodynamics law, conversion of energy is the essential feature of the physical process [21]. Dissipation of energy causes rock damage and yields strength loss. The energy damage variable is defined as the ratio of the unit dissipation energy to the critical dissipation energy. The critical variable has a damage variable of 1 . In practice, rock has a residual strength. Therefore, the damage value is not 1 . According to Jin et al. [22] the damage variable can be defined based on the dissipation of the material's constitutive energy. Hence, the damage variable is the ratio between dissipated energy and the material constitutive energy. In this paper, the constitutive energy is divided into elastic energy, plastic property, creep energy and fracture energy. It is considered that when the damage and fracture energy are clearly distinguished, the value of fracture energy can be neglected. However, the fracture energy is not only consumed in the form of dissipated energy but also released by thermal energy and acoustic energy. Initially, these values are small and almost negligible. However, damage occurred at the critical and residual stage of the rock. Instantaneously emits sound to release a large amount of heat. At this point, one can ignore the fracture energy. This method results in high damage value, and it can be seen from the repeated test of the single specimen that the repeated loading stress-strain curves in the residual phase can be well overlapped, indicating that there is a critical damage value. In this paper, the author modified the definition of damage variable by Jin et al. [22].

Wherefore, in the analysis and evaluation of rock mass stability critical and residual strength parameters are very important. Previously, conventional triaxial tests with multiple specimens were used to determine the residual strength of rocks. Single specimen method was rarely used to establish the residual and critical strength parameters.

\section{Methodology}

The single specimen multistage loading has been effectively used to establish the peak strength of the rocks [6]. Residual strength occurs at a very high strain. Consequently, the direct application of this method is problematic. Direct application of the residual strength stage will cause damage to the triaxial pressure chamber due to very large deformation.

Thence, this paper proposed repeated loading test on a single specimen. Typical stress-strain curve is shown in Fig. 1. The test procedures mainly categorized into two steps.

(1) After applying the initial confining pressure, the specimen is loaded to failure and then unloaded. The peak and residual strength parameters are determined accordingly.

(2) Set the confining pressure to the value of the above failure load, and repeat the loading until a steady residual stage reached and then unload, and increase the confining

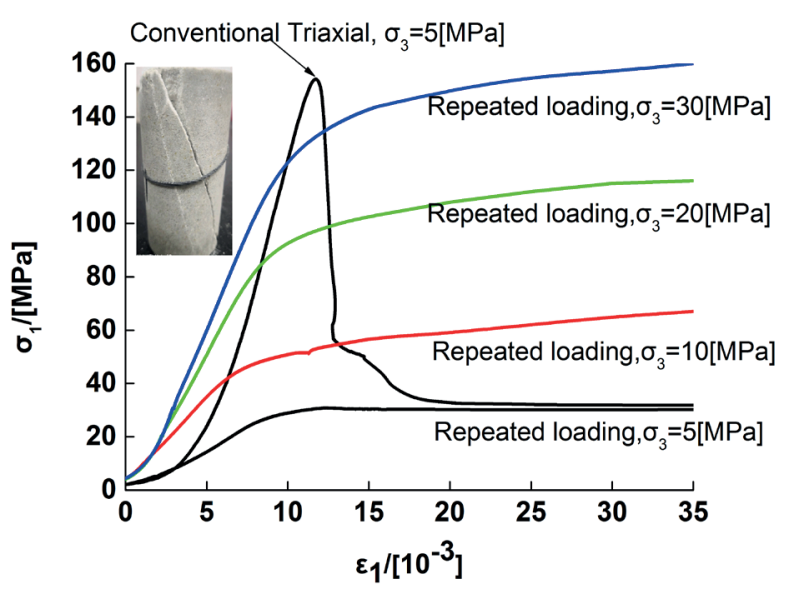

Fig. 1 Stress-strain relationships of repeated loading test on a single specimen 
pressure for different repeated loadings. 4 to 5 stages of repeated loadings are required to get appropriate residual shear strength parameters of rocks.

The accuracy and reliability of (the single specimen repeated loading) residual shear strength values can be evaluated based on the following three conditions.

(1) Under the same confining pressure, the single rock specimen repeated loading residual strength value should be the same as the conventional triaxial compression test result.

(2) For the failure rock samples by conventional triaxial compression, which are used for repeated loading at the same confining pressure, the residual strength obtained should be basically the same.

(3) If the failure rock sample by different stress paths is repeatedly loaded with the same confining pressure, the residual strength should be basically the same as the above (1).

Thus, (1) the conventional triaxial compression and single specimen repeated loading tests was designed accordingly. The testing program considered four confining pressures (5 $\mathrm{MPa}, 10 \mathrm{MPa}, 20 \mathrm{MPa}$, and $30 \mathrm{MPa})$. In the beginning, the conventional triaxial compression test was conducted to the residual strength stage and then unloaded. Then, a single specimen repeatedly was loaded at four different confining pressures.

(2) Comparative analysis was conducted for repeated loading and unloading triaxial tests. For different confining pressures (5 $\mathrm{MPa}, 10 \mathrm{MPa}, 20 \mathrm{MPa}$, and $30 \mathrm{MPa}$ ) the rock specimens were loaded to $70 \%$ of the peak strength value, and the confining pressures were unloaded to failure. Then, considering the above four confining pressures, the single specimen is repeatedly loaded. The specimens were loaded to the residual strength stage and then unloaded. Then the confining pressure was increased, and the specimen was loaded again.

(3) The shear strength index can be determined based on a linear regression method. The shear strength parameters can be evaluated based on the maximum shear stress and average normal stress relations or the maximum principal stress and minor principal stress relations. Chen et al. [23] recommended the later one. Similarly, this paper adopted the second method.

(4) The critical damage value was calculated by the constitutive energy of repeated loading test and the constitutive energy of the rock during the loading process. As it is shown in Eq. 1:

$$
\left\{\begin{array}{c}
D=\frac{U_{d}}{U}, \varepsilon<\varepsilon_{r} \\
D=1-\frac{U_{r}}{U}, \varepsilon \geq \varepsilon_{r}
\end{array} .\right.
$$

Where, $U_{d}$ is the dissipated energy, $U_{r}$ is the residual constitutive energy, $U$ is the constitutive energy during the loading fracture process.

Sandstone is a common type of rock in engineering. Therefore, to meet the objectives of this paper sandstone rock was used. A slightly weathered sandstone rock is brought from the Three Gorges reservoir area. It is a sericite medium quartz sandstone with a diameter of $50 \mathrm{~mm}$ and a height of $100 \mathrm{~mm}$. The specimens were screened by using wave velocity and density tests to minimize the variation of the specimens [3].

\section{Test results and discussion}

\subsection{Analysis of triaxial loading test}

Fig. 2 shows typical stress-strain curves for conventional triaxial compression and repeatedly loaded single specimen tests $\left(\sigma_{3}=30 \mathrm{MPa}\right)$.

As it can be seen from Fig. 2.

(1) Under different confining pressure conditions, the stress-strain curves for the conventional triaxial compression tests are the same, and there are consolidation, elastic, plastic, strain softening and residual strength stages. The confining pressure, the peak strength, and the residual strength increased from $5 \mathrm{MPa}$ to $30 \mathrm{MPa}, 152.87 \mathrm{MPa}$ to 270.40 $\mathrm{MPa}$, and 31.87 $\mathrm{MPa}$ to $151.35 \mathrm{MPa}$.

(2) Under different confining pressure conditions, the shape of the stress-strain curve of repeated loading is basically the same. After consolidation and elastic stages, the rock specimen quickly reached the plastic and the residual strength stage. The strain hardening phenomenon observed when the confining pressure increased, and the slope of the stress-strain curve gradually increased.

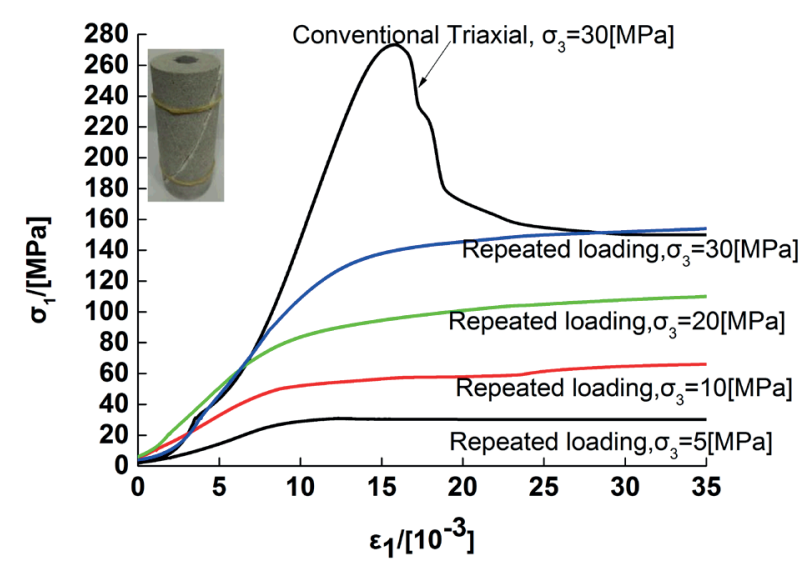

Fig. 2 Stress-strain relationships of conventional triaxial and repeated loading tests on a single specimen 
(3) The residual stress-strain curves overlapped when the confining pressure of repeated loading and conventional triaxial compression tests were equal. The deformation and strength characteristics of the residual stage didn't change, when the same confining pressure used for repeated loading.

Based upon Table 1:

(1) The discrepancy of the residual strength of the conventional triaxial compression test and repeated loading on the same confining pressure was between $1.15 \%$ and $5.14 \%$. With the same confining pressure, the rock specimens exhibited similar failure for repeated loading and conventional triaxial tests. It's good to meet the first condition mentioned in the above.

(2) Repeated loading of a $20 \mathrm{MPa}$ confining pressure failure rock sample in a conventional triaxial compression test, When the applied confining pressure was $5 \mathrm{MPa}, 10$ $\mathrm{MPa}, 20 \mathrm{MPa}$, and $30 \mathrm{MPa}$, compared with the residual strength obtained by using the conventional triaxial compression test, the variation was between $0.13 \% \sim 3.38 \%$. Moreover, the rock specimens in the conventional triaxial compression test showed a consistent trend of failure with repeated loading of $5 \mathrm{MPa}, 10 \mathrm{MPa}$, and $30 \mathrm{MPa}$ confining pressure failures. It is indicated that the destruction of rock samples by conventional triaxial compression are subjected to repeated loading tests of different confining pressures, and the residual strength obtained by repeated tests is approximately equal to the residual strength obtained by the conventional triaxial test. It shows that the destruction of rock sample by triaxial compression is repeatedly loaded, and its residual strength is mainly controlled by the confining pressure during repeated loading, but the relationship with the confining pressure of the initial loading failure is not obvious. It's also useful to meet the second condition specified in the above.

(3) Under different initial confining pressure conditions, the rock specimens went through shear failure. The entire repeated loading tests with different confining pressures yielded one macroscopic shear failure. It is indicated that the residual strength of the rock sample is controlled by the shear failure surface formed during the first conventional triaxial compression during repeated loading.

\subsection{Analyis of triaxial unloading test results}

Fig. 3 shows the stress-strain curve for the triaxial unloading and repeated loading tests. $\left(\sigma_{3}=30 \mathrm{MPa}\right)$

As shown in Fig. 3 and Table 2:

(1) The stress-strain curves of the repeated loading of the triaxial unloading and the conventional triaxial repeat loading can be well coincide. It shows that when the rock is at the same hydrostatic pressure, the residual strength of the rock mass has little relationship with its pre-peak stress path. It's used to meet the third condition mentioned in the above.

(2) Compared to the repeatedly loaded stress-strain curve the triaxial unloading has a lower residual stressstrain curve. The confining pressure at failure is significantly smaller than the initial confining pressure. When the repeated loading test is carried out, the confining pressure is applied to the initial value, which is equivalent to the increase of the loading confining pressure. Therefore, the residual strength of repeated loading is higher than the triaxial unloading test.

Table 1 Statistical results of conventional triaxial and repeated loading tests on a single specimen

\begin{tabular}{lcccccc}
\hline$\sigma_{3} /[\mathrm{MPa}]$ & \multicolumn{2}{c}{ Conventional triaxial test } & \multicolumn{4}{c}{ Repeated loading test on a single specimen } \\
\hline & $\begin{array}{c}\text { Peak strength/ } \\
{[\mathrm{MPa}]}\end{array}$ & Residual strength/ & $\sigma_{3} / 5$ & $\sigma_{3} / 10$ & $\sigma_{3} / 20$ & $\sigma_{3} / 30$ \\
& {$[\mathrm{MPa}]$} & {$[\mathrm{MPa}]$} & {$[\mathrm{MPa}]$} & {$[\mathrm{MPa}]$} & {$[\mathrm{MPa}]$} \\
5 & 152.87 & 31.87 & 30.23 & 60.89 & 110.33 & 151.17 \\
10 & 165.79 & 60.96 & 30.72 & 60.02 & 108.33 & 150.27 \\
20 & 250.55 & 105.34 & 31.83 & 58.90 & 106.57 & 150.69 \\
30 & 270.40 & 151.35 & 31.11 & 58.11 & 109.17 & 149.04 \\
\hline
\end{tabular}

Table 2 Residual Strength characteristics for different testing conditions

\begin{tabular}{|c|c|c|c|c|c|}
\hline$\sigma_{3} /[\mathrm{MPa}]$ & Conventional triaxial test & \multicolumn{4}{|c|}{ Repeated loading test on a single unloading failure specimen } \\
\hline & $\begin{array}{c}\text { Residual strength/ } \\
{[\mathrm{MPa}]}\end{array}$ & (1)/ [MPa] & (2)/[MPa] & (3)/ [MPa] & (4)/ [MPa] \\
\hline 5 & 31.87 & 30.91 & 30.45 & 31.04 & 30.64 \\
\hline 10 & 60.96 & 65.24 & 66.13 & 63.94 & 66.33 \\
\hline 20 & 105.34 & 105.49 & 107.22 & 109.48 & 108.28 \\
\hline 30 & 151.35 & 153.46 & 151.01 & 151.91 & 154.64 \\
\hline
\end{tabular}




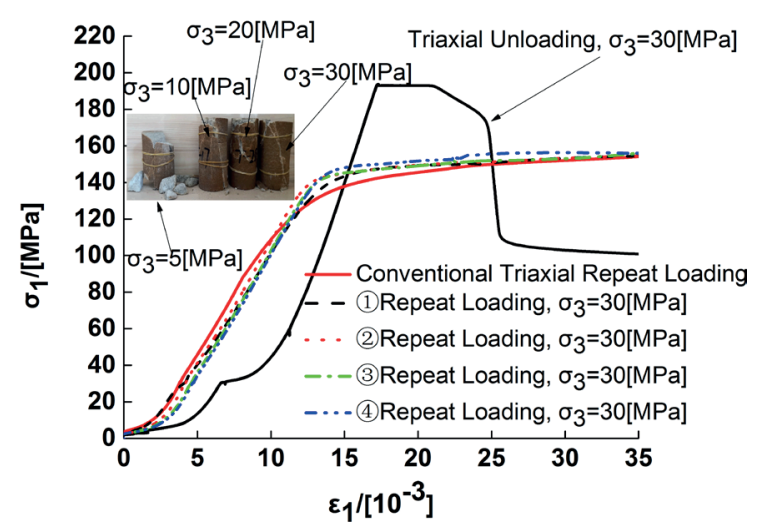

Fig. 3 Stress-strain relationships of triaxial unloading and repeated loading tests on a single specimen

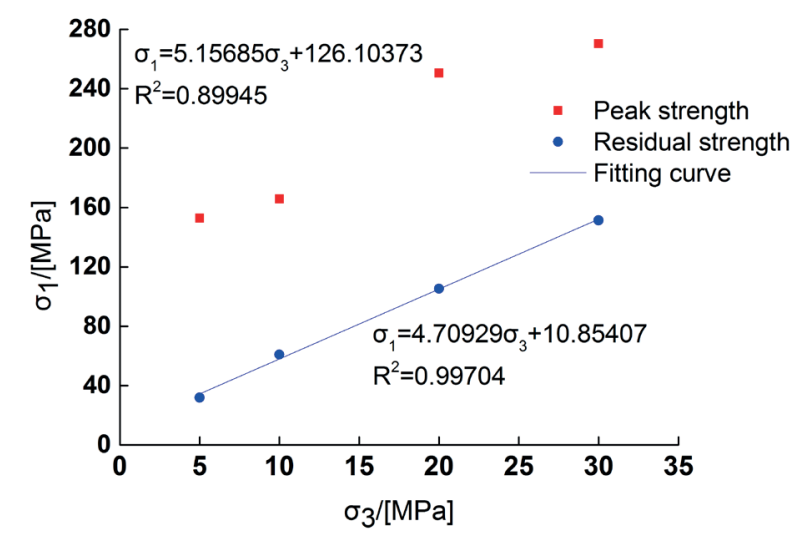

Fig. 4 Fitting curves for the conventional triaxial test

(3) Under different confining pressure and repeated loading, the fracture degree of the rock specimen in the triaxial unloading test is higher than the triaxial loading test. However, there is only one observed macroscopic shear failure throughout the testing stage Therefore, at the residual stage, the disintegration of rock had a trivial effect on the stress-strain curve. In the residual stage, a main shear plane controlled the strength and deformation of the rock specimen.

\subsection{Failure envelope characteristics analysis}

Figs. 4 and 5 show the best-fit curves for a repeated loading on a single specimen and conventional triaxial compression tests. The statistical results are summarized in Table 1. The resulting shear strength parameters are tabulated in Table 3.

Table 3 Strength characteristics for different testing conditions

\begin{tabular}{lcccccc}
\hline & \multicolumn{2}{c}{$\begin{array}{c}\text { Conventional } \\
\text { Failure } \\
\text { envelope }\end{array}$} & \multicolumn{2}{c}{ triaxial test } & \multicolumn{5}{c}{ Single specimen repeated loading } \\
test \\
acteristics & $\begin{array}{c}\text { Peak } \\
\text { strength }\end{array}$ & $\begin{array}{c}\text { Residual } \\
\text { strength }\end{array}$ & $\begin{array}{c}\sigma_{3} / 5 \\
{[\mathrm{MPa}]}\end{array}$ & $\begin{array}{c}\sigma_{3} / 10 \\
{[\mathrm{MPa}]}\end{array}$ & $\begin{array}{c}\sigma_{3} / 20 \\
{[\mathrm{MPa}]}\end{array}$ & $\begin{array}{c}\sigma_{3} / 30 \\
{[\mathrm{MPa}]}\end{array}$ \\
\hline$C /[\mathrm{MPa}]$ & 27.77 & 2.50 & 2.30 & 2.33 & 2.56 & 2.28 \\
$\varphi /[0]$ & 42.47 & 40.52 & 40.95 & 40.71 & 40.62 & 40.63 \\
\hline
\end{tabular}

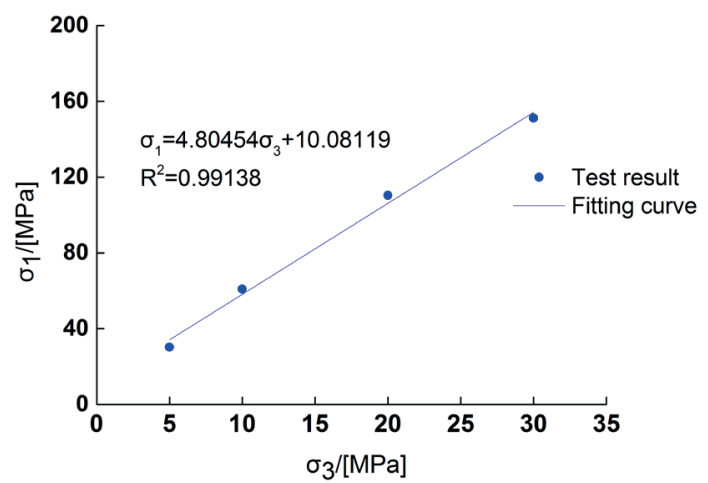

(a) $\sigma_{3}=5 \mathrm{MPa}$

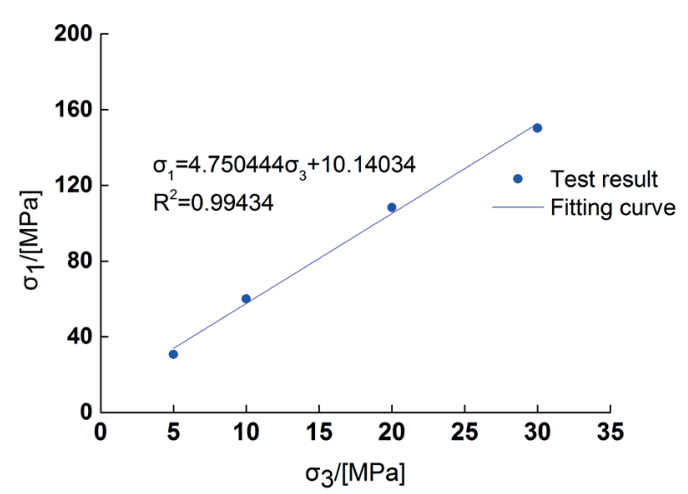

(b) $\sigma_{3}=10 \mathrm{MPa}$

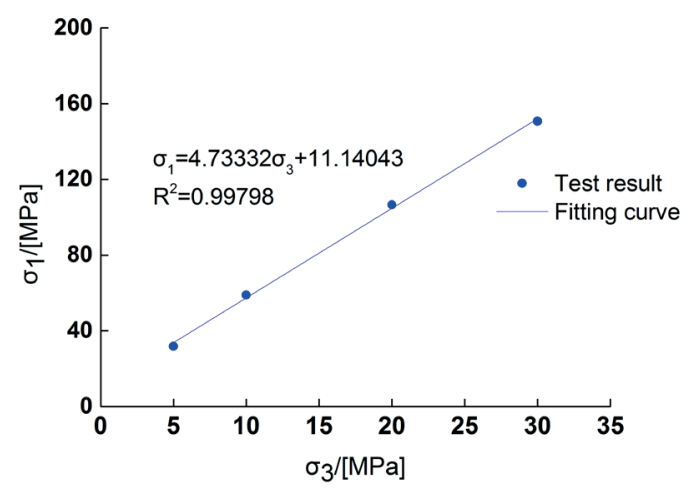

(c) $\sigma_{3}=20 \mathrm{MPa}$

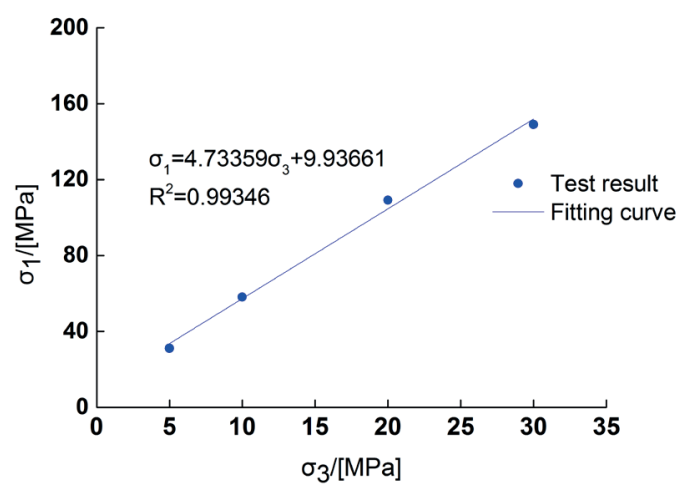

(d) $\sigma_{3}=30 \mathrm{MPa}$

Fig. 5 Fitting curve of single plunge repeated loading test 
Table 4 Energy and critical damage values with different confining pressures

\begin{tabular}{lccccc}
\hline $\begin{array}{l}\sigma_{3} / \\
{[\mathrm{MPa}]}\end{array}$ & $\begin{array}{c}U_{r} / \\
{\left[\mathrm{MJ} / \mathrm{m}^{3}\right]}\end{array}$ & $\begin{array}{c}U_{d} / \\
{\left[\mathrm{MJ} / \mathrm{m}^{3}\right]}\end{array}$ & $\begin{array}{c}U / \\
{\left[\mathrm{MJ} / \mathrm{m}^{3}\right]}\end{array}$ & $\begin{array}{c}D_{c} \\
\text { uncorrected }\end{array}$ & $\begin{array}{c}D_{c} \\
\text { corrected }\end{array}$ \\
\hline 5 & 0.94 & 1.52 & 1.54 & 0.99 & 0.39 \\
10 & 1.85 & 2.72 & 2.80 & 0.97 & 0.34 \\
20 & 2.99 & 3.92 & 4.11 & 0.95 & 0.27 \\
30 & 4.10 & 4.63 & 5.03 & 0.92 & 0.18 \\
\hline
\end{tabular}

Based upon Table 3, Fig. 4 and Fig. 5:

In the conventional triaxial compression test, the peak cohesive and internal angle of friction was $27.77 \mathrm{MPa}$ and $42.47^{\circ}$, respectively. Similarly, the residual cohesive and internal angle of friction was $2.50 \mathrm{MPa}$ and $40.52^{\circ}$. The residual cohesion based on repeated loading on a single specimen was between $2.28 \mathrm{MPa}$ and $2.56 \mathrm{MPa}$, which is different from the conventional triaxial compression test result. The variation was between $1.15 \%$ and $10.81 \%$. The internal angle of friction was between $40.6^{\circ} \sim 40.95^{\circ}$. The discrepancy was between $0.0031 \% \sim 1.10 \%$, which is too small. In the conventional triaxial compression test, the correlation coefficient for different stages was between $0.89 \sim 0.99$. However, repeated loading on a single specimen resulted in a higher coefficient of correlations $(>0.99)$. Repeated loading on a single rock specimen is used to determine the residual strength parameters.

Apart from its small variations in the testing results, this method (repeated loading on a single specimen) can be used to save the cost of site investigation.

\subsection{Study of critical damage value}

According to the conventional triaxial test result, typical calculated values are shown in Table 4.

From Table 4:

(1) As the confining pressure increases from $5 \mathrm{MPa}$ to $30 \mathrm{MPa}$, the residual constitutive energy and the dissipative constitutive energy increase from $0.94 \mathrm{MJ} / \mathrm{m}^{3}$ to $4.10 \mathrm{MJ} / \mathrm{m}^{3}$ and $1.52 \mathrm{MJ} / \mathrm{m}^{3}$ to $4.63 \mathrm{MJ} / \mathrm{m}^{3}$, respectively. The constitutive energy increased from $1.54 \mathrm{MJ} / \mathrm{m}^{3}$ to $5.03 \mathrm{MJ} / \mathrm{m}^{3}$. The corrected and uncorrected critical damage values decreased from 0.39 to 0.18 and 0.99 to 0.92 , respectively. The confining pressure has an inhibitory effect on the damage.

(2) The discrepancy between the uncorrected and corrected critical damage value is high.

\section{Discussion}

The critical value of the variable is called the percolation threshold. Percolation is a natural phenomenon. When the variable that plays a decisive role in the system reaches a threshold, the state of the system is abrupt. There exist percolation phenomenon and damage threshold in rock damage process under stress conditions. The renormalization group method is an effective method to study the percolation threshold [24-26]. Huang [27] obtained the critical damage value of 0.38 and 0.11 by using the renormalization group method based $2 \mathrm{~d}$ and $3 \mathrm{~d}$ models, respectively. The values are closer to the corrected damage threshold values of this paper. Liang et al. [25] used RFPA3D to simulate the sample loading failure test with different homogeneity and found the critical damage value between 0.25 and 0.35 , which is very close to the corrected critical damage value of this paper. The rock failure has self-organized critical characteristics, and a stress transfer was proposed in the self-organization degree parameter characterization unit [28]. The corresponding critical damage values (between 0.15 and 0.38 ) were close to the corrected damage threshold values in this paper. Therefore, it is reasonable to propose the modified damage variable in this paper.

From the above test result, the variation in the rock specimens mainly affects the deformation and strength characteristics of the pre-peak stage and has a slight effect on the residual strength. The residual strength is mainly controlled by the confining pressure. Su et al. [8] determined the strength parameters for sandstone and marble with a single specimen and found similar conclusion.

\section{Conclusions}

(1) Repeated loading on a single specimen was proposed to determine the residual strength index of rock. The analysis showed that the residual strength index obtained from repeated load test on a single specimen was consistent with the conventional triaxial compression test results. Repeated loading test on a single specimen is a relatively less dispersion, cheap and reliable method.

(2) The residual constitutive energy is obtained based on a single specimen method, and the corrected damage threshold values were in a better agreement with existing literature $[27,28]$.

(3) In the conventional triaxial compression tests, the peak and residual strengths have contained the variations in the rock specimens and the influence of confining pressure on the shear failure surface. The variation in the rock specimens is mainly due to pores and cracks within the body of the rock mass. During the loading process, the defects inside the rock sample gradually close or expand, resulting in significant differences in the stressstrain curve characteristics and peak strength of the rock 
sample. This variation in the test results often mentioned in the previous section. The macroscopic shear failure surface gradually developed when the loading stress exceeded the peak strength of the rock sample, and it controls the residual bearing capacity of the rock. For the same group of rock specimens, their mineralogical composition, particle structure, particle strength, and cementation properties are approximately the same. Thence, the shear strength and the shear failure surfaces of different rock specimens are naturally consistent. This further illustrates the rationality of the method (repeated loading on a single specimen) for determining the residual strength parameters of rock.

(4) It's important to point out that there are many types of rock masses in nature, which experience different forms of stress history. The rock samples used in this experiment

\section{References}

[1] You, M. Q., Hua, A. Z, Li, Y. S. "A study of triaxial strength and deformation of flawed specimen", Chinese Journal of Rock Mechanics and Engineering, 20(2), pp. 97-101, 1998. (in Chinese) [online] Available at: http://www.cnki.com.cn/Article/CJFDTotalYTGC802.025.htm [Accessed: 17.04.2019]

[2] Vásárhelyi, B., Kovács, D. "Empirical methods of calculating the mechanical parameters of the rock mass", Periodica Polytechnica Civil Engineering, 61(1), pp. 39-50, 2017.

https://doi.org/10.3311/PPci.10095

[3] Deng, H.-F., Li, J.-L., Deng, C.-J., Wang, L.-H., Lu, T. "Analysis of sampling in rock mechanics test and compressive strength prediction methods", Rock and Soil Mechanics, 32(11), pp. 3399-3403, 2011. (in Chinese)

https://doi.org/10.3969/j.issn.1000-7598.2011.11.032

[4] Deng, H.-F., Wang, Z., Li, J.-L., Hu, Y., Zhang, X. J. "Compressive Strength Correction Method of Flaw Sample in Rock Mechanics Test", Chinese Journal of Underground Space and Engineering, 13(2), pp. 307-313, 2017. (in Chinese) [online] Available at: http://www.cnki.com.cn/Article/CJFDTotal-BASE201702004.htm [Accessed: 17.04.2019]

[5] Kovari, K., Tisa, A. "Multiple Failure State and Strain Controlled Triaxial tests", Rock Mechanics and Rock Engineering, 7(1), pp. 17-33, 1975. Available at: https://link.springer.com/article/10.1007/ BF01239232 [Accessed: 17.04.2019]

[6] Kovari, K., Tisa, A., Einstein, H. H., Franklin, J. "Suggested Methods for Determining the Strength of Rock Materials in Triaxial Compression: Revised version", nternational Journal of Rock Mechanics and Mining Sciences and Geomechanics Abstracts, 20(6), pp. 283-290, 1983. https://doi.org/10.1016/0148-9062(83)90598-3

[7] Cain, P., Yuen, C. M. K., LeBel, G., Crawford, A., Lau, D. "Triaxial Testing of Brittle Sandstone Using a Multiple Failure State Method", Geotechnical Testing Journal, 10(4), pp. 213-217, 1987. https://doi.org/10.4095/304946 were micro-weathered, sericite quartz sandstone. A series of triaxial loading and unloading tests were conducted. The authors will continue further study on the applicability of this method to other types of rock masses with different lithologies and stress paths.

\section{Acknowledgement}

This work was supported by the National Nature Science foundation of China (No.51439003), National Nature Science foundation of China (No.51679127), the Research Fund for Excellent Dissertation of China Three Gorges University (No.2018BSPY002) and Key Laboratory of Geological Hazards on Three Gorges Reservoir Area (China Three Gorges University), Ministry of Education open fund project (No.2018KDZ04,No. 2018KDZ14).

[8] Su, C. D., You, M. Q. "Determination method of strength parameters for sandstone and marble with one specimen", Chinese Journal of Rock Mechanics and Engineering, 23(18), pp. 3055-3058, 2004 (in Chinese)

https://doi.org/10.3321/j.issn:1000-6915.2004.18.004

[9] Wu, Y. S., Li, J. "Single specimen method - A new method to determine the Coulomb curves of rocks", Chinese Journal of Geotechnical Engineering, 7(2), pp. 85-91, 1985. (in Chinese) [online] Available at: http:/www.cnki.com.cn/Article/CJFDTotal-YTGC198502008. htm [Accessed: 17.04.2019]

[10] Zhang, L., Wang B.-X., Yang, T. "The research of rock triaxial compression with multilevel confining pressure and the data statistics", Experimental Technology and Management, 25(2), pp. 43-47, 2008. (in Chinese)

https://doi.org/10.3969/j.issn.1002-4956.2008.02.014

[11] Cheng, H. X., Shen, M. R. "Triaxial test of a single block on a common liquid press", Chinese Journal of Rock Mechanics and Engineering, 6(1), pp. 39-46, 1987. (in Chinese) [online] Available at: http://www.cnki.com.cn/Article/CJFDTotal-YSLX198701004. htm [Accessed: 17.04.2019]

[12] Yan, M. L., Yang, Z. H. "Test study of the strength index of single specimen", Port Engineering, 2, pp. 13-19, 1991. (in Chinese) [online] Available at: http://www.cnki.com.cn/Article/CJFDTotalGKGC199102003.htm [Accessed: 17.04.2019]

[13] Xu, C., Wang, X. D., Zhang, C. S. "Experimental study of rock unloading strength parameters based on multiple failure method", Chinese Journal of Rock Mechanics and Engineering, 27(S1), pp. 2681-2686, 2008. (in Chinese) [online] Available at: http://www.cqvip.com/ QK/96026X/2008S1/1003994929.html [Accessed: 17.04.2019]

[14] Xu, Y., Li, Z. P., Ge, X. "Soft rock single test sample shear experiment methord", Journal of Liaoning Technical University, 25(3), pp. 367-368, 2006. (in Chinese)

https://doi.org/10.3969/j.issn.1008-0562.2006.03.015 
[15] Hou, Y., Sun, T. "An improved method to make the microdroplet single fiber composite specimen for determining the interfacial shear strength", Journal of Materials Science, 47(11), pp. 4775-4778, 2012. https://doi.org/10.1007/s10853-012-6317-2

[16] Yan, K. F., Zhang, C. Y., Qiao, S. R., Song, C. Z., Han, D., Li, M. "Measurement of In-Plane Shear Strength of Carbon/Carbon Composites by Compression of Double-Notched Specimens", Journal of Materials Engineering and Performance, 21(1), pp. 62-68, 2012 https://doi.org/10.1007/s11665-010-9823-x

[17] Liu, B. G., Cui, S. D. "Improvement of single specimen method for determination of rock strength parameters", China Civil Engineering Journal, 44(S1), pp. 162-165, 2011. (in Chinese) [online] Available at: http://www.cqvip.com/QK/90342X/2011S1/1003579335.html [Accessed:17.04.2019]

[18] Song, X. M. "The characteristics and improvement methods of strength parameters of rock are determined by single test method", Heilongjiang Science and Technology Information, 11, pp. 33-34, 2016. (in Chinese) https://doi.org/10.3969/j.issn.1673-1328.2016.11.031

[19] Pagoulatos, A. "Evaluation of multistage triaxial testing on Berea sandstone", Msc. Thesis, University of Oklahama, 2004.

[20] Zhang, Q. S., Yang, G. S., Ren, J. X. "New study of damage variable and constitutive equation of rock" Chinese Journal of Rock Mechanics and Engineering, 22(1), pp. 30-34, 2003. (in Chinese) https://doi.org/10.3321/j.issn:1000-6915.2003.01.005

[21] Xie, H. P., Ju, Y., Li, L. Y. "Criteria for strength and structural failure of rocks based on energy dissipation and energy release principles", Chinese Journal of Rock Mechanics and Engineering, 24(17), pp. 3003-3010, 2005. (in Chinese) https://doi.org/10.3321/j.issn:1000-6915.2005.17.001
[22] Jin, F. N., Jiang, M. R., Gao, X. L. "Defining damage variable based on energy dissipation", Chinese Journal of Rock Mechanics and Engineering, 23(12) ,pp. 1976-1980, 2004. (in Chinese) https://doi.org/10.3321/j.issn:1000-6915.2004.12.004

[23] Chen, L. H., Chen, Z. Y., Li, G. X. "Discussion of linear regression method to estimate shear strength parameters from results of triaxial tests", Rock and Soil Mechanics, 26(11), pp. 1785-1789, 2005. (in Chinese) https://doi.org/10.3969/j.issn.1000-7598.2005.11.016

[24] Duan, L. P., Lu, J. F., Chen, J., Li, Y. G. "Application of renormalization group theory to critical behavior of water", Journal of Chemical Industry and Engineering, 54(1), pp. 18-23, 2003. (in Chinese) https://doi.org/10.3321/j.issn:0438-1157.2003.01.004

[25] Liang, Z. Z., Tang, C. A., Tang, S. B., Xu, T., Zuo, Y. J. "Characteristics of fractal and percolation of rocks subjected to uniaxial compression during their failure process", Chinese Journal of Geotechnical Engineering, 29(9), pp. 1386-1391, 2007. (in Chinese) https://doi.org/10.3321/j.issn:1000-4548.2007.09.017

[26] de Alcantara Bonfim, O. F., Engelsberg, M. "Large-cell Monte Carlo renormalization-group method for a new type of environmental percolation", Physical Review B, 34(3), pp. 1977-1979, 1986. https://doi.org/10.1103/physrevb.34.1977

[27] Huang, M. H. "Rock damage evolution model and damage critical value theory and experimental study", Msc. Thesis, Central South University, 2003. (in Chinese) https://doi.org/10.7666/d.y637752

[28] Gao, Z. N., Yao, L. K., Xu, G. X. "Study on Self-organized CharacteristicsandCriticalityConditionintheCourseofRockFailure",Journal of Sichuan University, 41(2), pp. 91-95, 2009. (in Chinese) [online] Available at: http://en.cnki.com.cn/Article_en/CJFDTOTAL-SCLH 200902018.htm [Accessed: 17.04.2019] 